\title{
O projeto Bruxas Paulistas e a edição de processos eclesiásticos
}

DOl: http://dx.doi.org/10.21165/el.v49i1.2716

\section{Marcelo Módolo'}

\section{Resumo}

O Projeto Bruxas Paulistas constitui-se de um conjunto de treze processos eclesiásticos do século XVIII, fonte de pesquisa rica e pouco explorada de um trecho de nossa história ainda sombrio e pouco conhecido: a atuação indireta do Tribunal do Santo Ofício na região sudeste do Brasil. Igualmente, segundo Fernandes (2012), tais processos podem trazer uma significativa representação da língua falada para épocas pretéritas, captando variações já perceptíveis na oralidade, dada a preocupação do escrivão em registrar depoimentos ipsis litteris e com rapidez. A pesquisa ratifica, portanto - pela análise do processo de Santa Joana Gil - a importância de transcrever filologicamente essa documentação para se conhecer melhor a história desse período colonial brasileiro e resgatar possíveis indícios de variação e mudança linguística ocorridos no século XVIII.

Palavras-chave: feitiçaria, Tribunal do Santo Ofício; sudeste do Brasil; documentação formal; variação e mudança linguística.

1 Universidade de São Paulo (USP), São Paulo, São Paulo, Brasil; modolo@usp.br; http://orcid.org/0000-0001-5808-9368 


\title{
The Bruxas Paulistas project and the edition of ecclesiastical processes
}

\begin{abstract}
The Bruxas Paulistas ('São Paulo Witches') Project comprises the study of thirteen ecclesiastical trial proceedings dating from the eighteenth century, a major source to investigate how the Court of the Holy Office of the Inquisition played an indirect, yet significant role in Southeastern Brazil. This is a somber and still vastly unknown chapter in Brazilian history. Likewise, Fernandes (2012) has argued that these trial proceedings might provide new insights into the spoken language of specific periods in the past, and especially into variants that only later surfaced in other written records. This is due to the registrar's concern over recording testimonies' word by word as fast as he could. By taking one of these proceedings as a case study - the trial of Saint Joana Gil - this paper suggests that their adequate philological transcription is of paramount importance: it paves the way for capturing signs of variation and linguistic change in the eighteenth century and to better understand Brazil's colonial past.
\end{abstract}

Keywords: witchcraft, Court of the Holy Office of the Inquisition, southeastern Brazil, formal documentation, variation, and linguistic change.

\section{Introdução: a filologia de processos eclesiásticos}

O estudo filológico de processos eclesiásticos do século XVIII, corpus do Projeto Bruxas paulistas: edição filológica de documentação sobre feitiçaria² (daqui em diante, "Projeto"), está sendo realizado sob a perspectiva da curadoria textual, metodologia pela qual o filólogo cumpre o papel de restaurador dos textos, segundo Ferreira (2016). O curador textual administra o bem de outrem, mas não é coautor desse texto, ou seja, não edita um texto arbitrariamente. A filologia como curadoria torna-se, portanto, uma atividade nos termos da qual o filólogo tem a seu cargo a tarefa de cuidar de algo, isto é, de uma parte, ou da totalidade, de patrimônio alheio, que, neste caso, é o texto criado por um outro autor ou, no nosso caso, outros autores. Há normas e escolhas editoriais a seguir. Especificamente no Projeto, empregamos edições semidiplomáticas, cópias conservadoras de uma perspectiva editorial.

Há uma série de razões para identificar, restaurar e editar esses documentos do século XVIII. Já de partida, trata-se da conservação e divulgação de textos que têm muito a dizer sobre um período significativo para a história da sociedade e da cultura da América portuguesa, segundo Mary Del Priori, apud Boccia (1999). Afinal, como bem aponta Burke

2 Algumas repercussões desse Projeto podem ser lidas em: Cruz (2014), Ferrari (2015), Ferreira (2019), Hebmüller (2014), Módolo e Negro (2018), Morais (2018). 
(1992, p. 337), deparamo-nos com descrições insuficientes do que realmente aconteceu nesse período, o que nos obriga a encontrar novas formas narrativas como fontes primárias de pesquisa, categoria em que se enquadra a documentação que se tem em mira.

Processos eclesiásticos do século XVIII são, mais particularmente, uma fonte rica e pouco explorada de documentação para pesquisas linguísticas sobre o português brasileiro. Uma de suas principais vantagens epistemológicas, para esse tipo de investigação, é o fato de que, nos depoimentos, o escrivão estava obrigado a reproduzir o que era dito pela testemunha - o que pode ser considerado o depoimento propriamente dito -, momento em que muito possivelmente prestava pouca atenção ao que fosse considerado norma culta na época, dada a rapidez com que eram tomados tais testemunhos.

Para o leitor atento, marcas de oralidade e desvios da norma linguística de então podem já sinalizar futuras derivas linguísticas, que se tornam datáveis ao menos a partir dessa época. Evidentemente, com isso não se pretende que todas as questões serão resolvidas a contento. Basta, para tanto, lembrar a máxima laboviana de que trabalhar com dados históricos é "[a] arte de fazer o melhor uso de maus dados" (LABOV, 1982, p. 20), metáfora mais que apropriada para definir o tipo de dados de que dispõem os que trabalham no campo da linguística histórica e filologia portuguesa.

Dessa forma, conclui-se que há relevantíssimo interesse sócio-histórico e também linguístico na edição dessas fontes documentais, evidenciando um potencial antes não percebido que tais fontes primárias carregam para fazer avançar pesquisas nesses setores.

\section{Os processos em edição no Bruxas Paulistas: materiais e métodos}

Os materiais empregados para as transcrições são fac-símiles dos 13 processos eclesiásticos encontrados no Arquivo da Cúria Metropolitana Dom Duarte e Silva da cidade de São Paulo, no fundo intitulado Documentação Varia, Processos Manuscritos (1640-2009). Por sua vez, os métodos empregados para a transcrição de tais processos têm sido as normas estabelecidas pela Comissão de elaboração de normas para transcrição de documentos manuscritos do Projeto para a História do Português Brasileiro apresentadas igualmente por Megale e Toledo Neto (2005); vide anexo. Tal regramento constituise em um conjunto inicial de dezesseis preceitos para a elaboração de uma edição semidiplomática, a ser devidamente adaptado, vale dizer, alterado, complementado ou suprimido (quando houver pontos desnecessários), em função do exame cuidadoso da documentação a ser editada.

Dos processos fotografados e editados de modo fac-similar, dispomos atualmente da transcrição semidiplomática de sete textos, seis dos quais apresentamos resumidamente 
no Quadro 1, abaixo. Para evitar anacronismos, destacamos que a Diocese de São Paulo, fundada em 1745, era responsável por um conjunto maior de cidades e lugarejos, alguns dos quais atualmente estão distribuídos em episcopados distintos. Como fruto dessa reorganização, a partir de 1989, mas não antes disso, a Cúria passou a armazenar apenas a documentação referente às atuais 287 paróquias da Arquidiocese de São Paulo. Para maior detalhamento, vide o estudo de Zanon (1999).

Quadro 1. Processos já editados

\begin{tabular}{|l|l|}
\hline \multicolumn{1}{|c|}{ Réus } & \multicolumn{1}{|c|}{ Resumo } \\
\hline $\begin{array}{l}\text { Inácia Siqueira, Martinha de } \\
\text { (1770) - Itapetininga, SP. }\end{array}$ & $\begin{array}{l}\text { Inácia de Siqueira, Martinha de Siqueira e Isidoro de Siqueira, } \\
\text { indígenas, foram acusados por usar a imagem de Santa } \\
\text { Ana para pedir esmolas em Itapetininga. Com o dinheiro } \\
\text { arrecadado faziam comércio de bolos ao som de batuques. } \\
\text { As testemunhas do processo também disseram que eles } \\
\text { realizavam feitiços, assim como os que frequentavam o } \\
\text { grupo de pessoas que faziam e ouviam os batuques. Vários } \\
\text { membros da comunidade ficaram doentes e os réus foram } \\
\text { apontados como a causa dos incidentes. } \\
\text { (Transcrição da Profa. Dra. Helena de O. B. Negro.) }\end{array}$ \\
\hline Páscoa (1749) - São Paulo, SP. & $\begin{array}{l}\text { A escrava Páscoa é acusada de matar diversas pessoas e } \\
\text { de ter pacto com o diabo. O auto de devassa afirma que na } \\
\text { casa em que morava foram desenterrados "malefícios", que } \\
\text { eram compostos por ossos de galinha e aparos de unhas } \\
\text { embrulhados em um papel escrito por uma das vítimas. } \\
\text { (Transcrição da Profa. Dra. Helena de O. B. Negro.) }\end{array}$ \\
\hline $\begin{array}{l}\text { Patrício Bicudo da Silva (1749) - } \\
\text { Santana de Parnaíba, SP. }\end{array}$ & $\begin{array}{l}\text { Patrício, escravo liberto, mulato, solteiro, 26 anos, é acusado } \\
\text { de "arte mágica": curandeirismo especializado no trato de } \\
\text { mordedura de cobra. Sua arte é dotada de uma ritualística } \\
\text { que mescla elementos naturais e sobrenaturais. No campo } \\
\text { dos elementos naturais manifesta-se a limpeza do local da } \\
\text { mordedura, eliminando as possíveis contaminações que } \\
\text { o ataque do ofídio poderia promover e um "tratamento" } \\
\text { com o sumo de folhas mascadas. Em relação ao mágico, } \\
\text { sobrenatural, Patrício carrega consigo uma cobra viva junto } \\
\text { ao corpo que ele manuseia durante o rito de cura. } \\
\text { (Transcrição do Prof. Fábio Garcia Dias.) }\end{array}$ \\
\hline
\end{tabular}




\begin{tabular}{|l|l|}
\hline $\begin{array}{l}\text { Joana e Isabel (1759) - Santos, } \\
\text { SP. }\end{array}$ & $\begin{array}{l}\text { Joana e Isabel usavam de feitiçaria para matar pessoas. } \\
\text { Uma das testemunhas afirma que encontrou uma panela } \\
\text { cheia de raízes, ossos e folhas enterrada na entrada do } \\
\text { sítio de senhor de Joana e Isabel. O intuito dessa magia era } \\
\text { amofinar Bento de Castro e matar sua esposa. } \\
\text { (Transcrição da Profa. Dra. Helena de O. B. Negro.) }\end{array}$ \\
\hline $\begin{array}{l}\text { Leonor de Siqueira e Ana } \\
\text { Francisca (1771) - São Paulo, SP. }\end{array}$ & $\begin{array}{l}\text { Leonor de Siqueira e sua filha Ana Francisca são acusadas } \\
\text { de realizar feitiçarias para transformar Manoel José Barreto, } \\
\text { marido de Anna Francisca, em pateta. O documento conta } \\
\text { com relatos das testemunhas arroladas no caso. } \\
\text { (Em processo de edição.) }\end{array}$ \\
\hline $\begin{array}{l}\text { Tereza Leite e Escolástica Pinta } \\
\text { da Silva (1754) - Jundiaí, SP. }\end{array}$ & $\begin{array}{l}\text { Tereza Leite e Escolástica Pinta da Silva foram acusadas de } \\
\text { feitiçaria e da morte de Manoel Garcia, marido de Escolástica } \\
\text { e genro de Tereza Leite. Além de serem acusadas de } \\
\text { feitiçaria e de terem pacto com o demônio, diziam que elas } \\
\text { provocavam doenças sucessivas na vítima. Também foram } \\
\text { acusadas da morte de outros dois homens }\end{array}$ \\
\hline
\end{tabular}

Fonte: Elaboração própria

\section{O Processo de Santa Joana Gil: sua sócio-história}

O povoado de Mogi Mirim, que era habitado por índios caiapós, surgiu por volta de 1720, com a passagem de bandeirantes paulistas que se dirigiam ao estado de Goiás em busca de ouro. Esse arraial, então chamado de Mojimirim (nome que se originou do tupi antigo moîymirim, "pequeno rio das cobras"), já possuía bom número de habitantes em 29 de julho de 1747, quando começaram a ser cavados os alicerces da primitiva igreja Matriz de São José. Com a construção da matriz, a freguesia foi criada em 1751, desmembrada da então freguesia de Nossa Senhora da Conceição do Campo, atual Mogi Guaçu.

Foi nessa freguesia que Joana e Lucrécia Gil, primas, agiam em conjunto no Sítio das Caveiras, bairro das Caveiras. A "Denuncia ex officio" de 1758 relata uma longa acusação contra essas mulheres (847 linhas de texto) que diziam promover milagres, quando afirmavam que as imagens de Jesus Cristo e de Nossa Senhora do Rosário se deslocavam do oratório até a cama de Joana e que Ihes passavam mensagens premonitórias, anunciando um grande castigo para a freguesia. Além disso, tais estátuas apareciam manchadas de sangue, que escorria por seus olhos, roupas e ouvidos. O acontecimento espalhou-se na vila, e a distribuição de partes das vestes dos santos foi realizada entre os

3 Este processo encontra-se já editado e estudado por Porto (2019). 
moradores, que acreditavam no suposto milagre e no dom premonitório das acusadas. No final, as acusadas foram absolvidas e apenas sofreram a pena de serem castigadas pelo tio, Manoel Antonio Gil:

\author{
${ }^{4}$ Rezolvi, e aconselhei ao dito Manoel \\ Antonio Se RetiraSse para caza, e castigaSse \\ bem a ambas denunsiadas; e lansaSse de \\ $700^{5}$ Sua imaginacão fóra o erroneo conceyto em \\ que estava de Serem verdadeyras Revelacoens \\ e veradeyros milagres os que noticiava \\ e que naõ publicasse cousa algũa Sobre a mate- \\ ria, por evitar Cisma; e que naõ parando \\ 705 os milagres, nem elle paraSse com as afroy- \\ taz; e que de qualquer novidade que houveSse \\ me tornaSse fielmente a noticiar, para pro- \\ ver-Ihe o Remedio: ASsim prometeo cumprir \\ o dito Manoel Antonio, e com effeyto (me cont- \\ 710 tou) castigara a ambas denunsiadas;
}

A "Denuncia" corrobora os estudos de que não houve - no sudeste da América lusa - visitação oficial do Tribunal do Santo Ofício, nos moldes como tivemos no norte e nordeste, conforme Assis (2002, p. 52-53):

A presença da Inquisição no Brasil relaciona-se à atitude de expansão dos órgãos de controle do próprio Estado. Lembremos, contudo, que o Brasil estava sob a tutela do Tribunal do Santo Ofício de Lisboa, não havendo a instauração formal de um tribunal inquisitorial específico para a América portuguesa, limitando-se a visitações esporádicas e à presença de familiares do Santo Ofício. Das três visitações conhecidas ao Brasil - 1591-1595 (Bahia, Pernambuco, Itamaracá e Paraíba), 1618-1620 (Bahia) e 1763-1769 (Grão-Pará) -, é significativo que as duas primeiras ocorressem durante o período de União Ibérica, o que parece representar mais uma política de ideologia expansionista do governo filipino do que aquela até então seguida pelos portugueses.

4 A transcrição empregada neste estudo foi elaborada pelas Prof.as Dr.as Helena de O. B. Negro, Nathalia R. Fernandes e pelo Prof. Fábio Garcia Dias.

5 Esta numeração feita de cinco em cinco linhas corresponde às linhas originais do processo transcrito. 
Os inquisidores, por seu turno, nomeavam clérigos que seriam os responsáveis pelo controle dos hábitos e costumes na colônia portuguesa, cujo objetivo principal era exterminar toda prática adversa ao catolicismo, fato verificado nesse processo mogimiriano que evocava poderes sobrenaturais às acusadas. Não só os padres eram orientados a observar o comportamento dos fiéis; além deles, qualquer pessoa poderia acusar outra, inclusive anonimamente, o que propiciava a vingança entre vizinhos ou parentes em decorrência de desavenças cotidianas. Havia uma lista preparada pela Igreja na qual constavam os que eram considerados crimes de heresia, dentre os quais se incluíam feitiçaria, práticas judaicas, bigamia, adultério, sodomia, entre outros, conforme já apontado por Siqueira (1978), Novinsky (1978, 1992a, 1992b e 2002) e Mendonça e Moreira (1980).

Nessa mesma esteira, uma das testemunhas, Francisco da Costa Leme, atesta que a família Gil era mordida de judaísmo:

620 ouvira murmurar Sobre o apelido de Gil

deSsa forma: que Serto homem em Mogi GuaSsú

[...]n pedira o casamento de hum filho Seu pa

ra que naõ cazaSse nesta famiLia, dizendo

Ser mordida de Judaismo, por talvez deSender

625

de outro Gil mal opinado na villa de Tabua

the, de donde fugira, e chamavaSse o dito ho-

Desse modo, os principais perseguidos, os considerados hereges, eram curandeiros e especialmente judeus convertidos - os cristãos novos - pois se acreditava que mantivessem às escondidas seus costumes religiosos, conforme sugere o excerto acima. Vale lembrar que os primeiros habitantes do território eram os índios, cujas práticas de cura de enfermidades iam sendo disseminadas pelos novos habitantes, dando origem aos curandeiros, então perseguidos. Essa argumentação coaduna-se ainda com a origem das investigadas, que eram bastardas e de origem indígena, provavelmente caiapós, portanto, reforçavam eventuais suspeitas de algum tipo de heresia:

335 Testemunha por ouvir conten[...]or[...]

Pay Declarou outro Sim emquanto as vir

tudes, vida, e custumes e qualidade da[s] De

nunciadas que nada Sabia Só Sim que S[a]o

Bastardas, oriundas do Gentio da terra o que 
Esse processo seguiu as seguintes etapas: (i) a denúncia feita pelo promotor eclesiástico, contendo a descrição do suposto crime contra a Igreja; (ii) os testemunhos tomados de cinco pessoas que teriam presenciado os fenômenos; (iii) as decisões tomadas pelo juiz eclesiástico encarregado do caso, que recomenda uma coça às moças. Essa organização tripartite refletia - em seus pormenores - a legislação presente nas Ordenações Filipinas (sancionadas em 1595, tendo entrado em vigor em 1603), codificação que vigorava tanto no Brasil como em Portugal, trazendo, em seu livro $V$, disposições sobre crimes. Para o caso em tela, destacam-se a apostasia (adoção de outra religião pelo cristão) e a feitiçaria (que incluía a adivinhação e a invocação de espíritos). As penas variavam desde o confisco de bens até a condenação à morte na fogueira, pois se pregava que o fogo queimaria os pecados e expurgaria o espírito demoníaco possuidor do corpo do condenado, dando uma nova vida ao espírito.

Os juízes eclesiásticos funcionavam como peritos que avaliavam a existência de ofensa à religião, de modo a evitar a condenação de inocentes. A condenação era proferida pelo Santo Ofício em processo secreto, e a execução das penas era de competência dos juízes comuns, daí a correlação com as Ordenações. No Brasil, o Santo Ofício não chegou a se estabelecer verdadeiramente, não obstante houvesse juízes eclesiásticos.

\section{O Processo de Santa Joana Gil: algumas contribuições da morfossintaxe}

Em relação aos cinco testemunhos respectivamente de Manoel Antonio Gil, Antonio Correa Rangel, Pedro Frazaõ de Brito, Manoel Brito Leme e Francisco da Costa Leme há de destacar, não de forma exaustiva, alguns traços morfossintáticos, merecedores de exploração ulterior, nesse documento setecentista (e talvez no conjunto dos treze processos), negritados abaixo:

(1) O documento apresenta oscilações entre usos perifrásticos de estar + gerúndio e estar + infinitivo, como em:

173 , para hir ver

a Sobredita Denunçiada Joana a horas que

estava dormindo em Sua cama,

177 mam, emsima do do Peito e que a dita Imagem

viera do Oratorio em que estava por virtude

própria a fazer companhia, e a distançia ad[...] 
295 ter [de] noyte com a dita Denunçiada em Sua Cama estando ella dormindo, e faze[r]em Se [V]istas ditas Imagens em Sima do Peyto e mam da mesma Denunçiada, e que ella des

(2) Apagamento do SN na função de sujeito, como em:

220 Denunciadas: outro Sim mais Ødeclarou que d[e] conselho, e inSinuaçaõ de Seu Reve

(3) Regências verbais distintas:

145 Saõ Joze de Mogi Mirim e na mesma caza de que vive de Suas Lavouras de cha que disse

172 fora ele Testemunha chamado, e advertido $\mathbf{d e}^{6}$ Sua filha, por nome Lucreçia, para hir ver a Sobredita Denunçiada Joana a horas que

(4) Usos de clíticos proclíticos:

285 za de Manoel Antonio Gil, morador no Bayr ro das caveyras, desta Freguezia, Se achava morando a denunçiada Sobrinha do mesmo; e Sabia mais que neSse mesmo tempo da Sua ReSidençia Se espalhara pela mesma

400 ços, a Imagem de Christo, Ihe Revelara, e comunicaraõ o castigo grande que estava

6 Fato comum no português arcaico é a inserção do agente da passiva pela preposição "de". 
(5) Apagamento de concordância no sintagma nominal:

424 [hi]aõ admirar as prodigiosa que ReSaSsem ca

da hum Sete autos de contriçaõ e o que Sabia

427 ca d[a] Denunçiada: e que naõ Sabia c[oi]za

alguma emquanto $\mathbf{a} \emptyset$ virtudes, vida e cus

tumes da mesma Denunçiada Só Sim

(6) Não observância da concordância de gênero:

424 [hi]aõ admirar as prodigiosa que ReSaSsem ca

da humø Sete autos de contriçaõ e o que Sabia

595 mesmas Imagens e esta Sangue de má cheyro;

e diziaõ ellas Denunçiadas que verteraõ as di

tas Imagens por naõ quereram os moradores

Os seis exemplos observados acima podem indiciar que as seis variáveis identificadas constituam algumas particularidades sintáticas do português transplantado para a região leste de São Paulo.

A título de exemplificação, a consulta a outros documentos antigos dessa região poderia confirmar ou não fatos interessantes como a não observância da concordância de gênero que apontamos nas linhas 425 e 595. Quando tratamos da falta de concordância, seja ela qual for, na Sociolinguística, o fenômeno costuma ser associado de pronto aos grupos sociais desprestigiados. A falta de concordância de gênero, no entanto, não é um fenômeno comum a todos esses grupos, sendo encontrada, segundo estudos especializados, apenas em ambientes que foram alvos de um intenso contato linguístico. No caso presente, poderíamos aventar o contato forte com índios caiapós da região. É, aliás, fortalecida a hipótese de uma relação entre a variação de gênero e o contato linguístico, quando levamos em conta o fato de que as línguas crioulas de base portuguesa foram fortemente afetadas pelo fenômeno morfossintático do qual estamos tratando, vide Lucchesi, Baxter e Ribeiro (2009).

Outra metodologia que poderia vir a ser empregada, para a abonação de eventuais particularidades morfossintáticas como traços do português transplantado para a região leste de São Paulo, seria a gravação de falantes dessa região, de preferência pessoas 
idosas, analfabetas, residentes em povoados os mais afastados da mídia. Com isso, juntar-se-iam dados de língua escrita e de língua falada, para um trabalho conjunto de maior envergadura, dialetológico, como já proposto pelo Projeto Filologia Bandeirante, vide Megale (1998). Seria um trabalho fundamentalmente filológico, na medida em que vai às fontes, tanto por meio da pesquisa histórica, antropológica e social, como pela busca da ancianidade dos traços morfossintáticos da língua nessa região; ainda assim, seria igualmente um trabalho linguístico, é claro, visto que sua base se assentaria em uma pesquisa linguística de campo.

\section{Conclusões}

As conclusões que se impõem, por enquanto, estão mais para perguntas do que respostas. São hipóteses que cobram pesquisas, a ver se se confirmam.

Em um primeiro momento, a publicação desses processos dá voz à função transcendente da filologia como ciência, ou seja, desenvolve um tema de natureza histórica: a presença de representações do Santo Ofício na região sudeste do que era então a América portuguesa e veio a se tornar o Brasil. Por meio de um olhar severo, arcebispos e bispos católicos deveriam nomear um clérigo em cada paróquia, com dois, três ou mais seculares, cuja função seria inquirir sobre a existência de qualquer pessoa suspeita do crime de heresia. Ainda, segundo Herculano (1960, p. 39): "Os barões ou senhores das terras e os prelados das ordens monasticas ficavam, além disso, obrigados a procurálos nos districtos ou territorios da sua dependencia, nos povoados e nas selvas, nas habitações humanas e nos esconderijos e cavernas".

Igualmente, esses vários processos recuperam vozes outras. Em que pese a opressiva mediação institucional da Inquisição, esse Projeto permitirá aos historiadores entrever o não dito por meio do dito, isto é, perceber, até onde for possível, aspectos da sociedade colonial paulista implícitos em palavras e eventos registrados nesses documentos. Pensamos, por exemplo, no lugar e na condição da mulher nessa sociedade tão estratificada em que prepondera o poder do homem, especialmente entre os brancos.

Tais pesquisas poderão ainda acenar para eventuais soluções relativas às diversas questões levantadas pela literatura linguística contemporânea, como i) a da procedência dos portugueses que para cá trouxeram a língua; ii) a da retenção linguística de traços desse português ou do português resultante do contato com línguas diversas: indígenas ou africanas - conforme já explorado em Oliveira, Zanoli e Módolo (2019); ou iii) a das transformações linguísticas (variação e mudança) pelas quais a língua passou em seu processo histórico em nosso país. 


\section{Agradecimentos}

O presente trabalho foi realizado com apoio de bolsa de produtividade em pesquisa do CNPq - nível 2 (processo número 308793/2019-6) concedida ao autor.

\section{REFERÊNCIAS}

ASSIS, A. A. F. de. Inquisição, religiosidade e transformações culturais: a sinagoga das mulheres e a sobrevivência do judaísmo feminino no Brasil colonial - Nordeste, séculos XVI-XVII. Revista Brasileira de História, São Paulo, v. 22, n. 43, p. 47-66, 2002. Disponível em: https://bit.ly/2nsEXLX. Acesso em: 28 set. 2019.

BOCCIA, S. As bruxas paulistas. Revista Veja, São Paulo: Editora Abril, ed. 1619, 13/10/1999.

BURKE, P. A história dos acontecimentos e a história da narrativa. In: BURKE, P. A escrita da história: novas perspectivas. São Paulo: Editora da Unesp, 1992.

CRUZ, F. Magia negra. Revista aventuras na história, São Paulo, Perfil, 2014.

FERNANDES, N. R. Sujeito nulo na história do português de São Paulo: 1878-1947. 2012. Dissertação (Mestrado em Filologia e Língua Portuguesa) - Faculdade de Filosofia, Ciências e Letras, Universidade de São Paulo, São Paulo, 2012. Disponível em: https://bit. ly/2nsNKxy. Acesso em: 28 set. 2019.

FERREIRA, I. Bruxas paulistas: pesquisa resgata história de mulheres acusadas de feitiçaria. Jornal da USP. Disponível em: https://bit.ly/2XNWfDk. Acesso em: 18 mar. 2020.

FERREIRA, P. T. Filologia como curadoria: o caso Pessoa. Filologia e linguística portuguesa, São Paulo, v. 18, n. 2, p. 231-262, ago./dez. 2016. Disponível em: https://bit.ly/2kqfLob. Acesso em: 18 mar. 2020.

FERRARI, M. Privilégios ancestrais: livro sobre a justiça em São Paulo na época colonial descreve as raízes dos desmandos públicos no Brasil. Revista pesquisa Fapesp, São Paulo, ed. 234, ago. 2015. Disponível em: https://revistapesquisa.fapesp.br/2015/08/13/ privilegios-ancestrais/. Acesso em: 18 mar. 2020.

HEBMÜLLER, P. Arquivos da Cúria mostram reflexos da Inquisição no Brasil do século 18. Jornal da USP. 2014. Disponível em: https://bit.ly/3evQXIZ. Acesso em: 18 mar. 2020. 
HERCULANO, A. História da origem e estabelecimento da Inquisição em Portugal. 13. ed. Tomo I. Lisboa: Livraria Bertrand, 1960.

LABOV, W. Building on empirical foundations. In: LEHMANN, W., MALKIEL, Y. (ed.). Perspectives on historical linguistics. Amsterdan/Philadelphia: John Benjamins, 1982. p. 17-92.

LUCCHESI, D.; BAXTER, A.; RIBEIRO, I. (org.). O português afro-brasileiro. Salvador: EDUFBA, 2009.

MEGALE, H. Filologia bandeirante. Itinerários, Araraquara, n. 13, p. 11-34, 1998.

MEGAlE, H.; TOLEDO NETO, S. A. (org.). Por minha letra e sinal: documentos do ouro do século XVII. Cotia: Ateliê Editorial; FAPESP, 2005.

MENDONÇA, J. L. D.; MOREIRA, A. J. História dos principais actos e procedimentos da Inquisição em Portugal. Lisboa: Imprensa Nacional Casa da Moeda, 1980.

MÓDOLO, M.; NEGRO, H. de O. B. Autos de denúncia da Cúria Metropolitana de São Paulo: análise do uso de sinais diacríticos na escrita de processos de feitiçaria. Estudos Linguísticos, v. 47, p. 435-445, 2018.

MORAIS, K. Jundiahy, 1754: mãe e filha são julgadas por FEITIÇARIA. Jundiaí agora: opinião. Jundiaí, 31 de outubro de 2018. Disponível em: http://jundiagora.com.br/jundiahyfeiticaria/. Acesso em: 18 mar. 2020.

NOVINSKY, A. Inquisição: prisioneiros do Brasil. Rio de Janeiro: Editorial Expressão e Cultura, 2002.

NOVINSKY, A. Inquisição. Ensaios sobre mentalidades, heresias e arte. Rio de Janeiro: Editorial Expressão e Cultura, 1992a.

NOVINSKY, A. Inquisição. Rol dos culpados. Rio de Janeiro: Editorial Expressão e Cultura, 1992b.

NOVINSKY, A. Inquisição: inventários de bens confiscados a cristãos novos no Brasil. Lisboa: Editorial Imprensa Nacional. Casa de la Moneda, 1978. 
OLIVEIRA, M. S. D. de; ZANOLI, M. de. L.; MÓDOLO, M. O conceito de Língua Geral do Brasil revisitado à luz da linguística de contato. Journal of ibero-romance creoles, v. 9, p. 306-333, 2019

PORTO, N. P. Feitiçaria paulista: transcrição de processo-crime da Justiça Eclesiástica na América portuguesa do século XVIII. 2019. Tese (Doutorado em Letras) - Faculdade de Filosofia, Ciências e Letras, Universidade de São Paulo, São Paulo. Disponível em: https://teses.usp.br/teses/disponiveis/8/8142/tde-02052019-112854/publico/2018_ NarayanPereiraPorto_VCorr.pdf. Acesso em: 18 mar. 2020.

SIQUEIRA, S. A. A Inquisição portuguesa e a sociedade colonial. Coleção Ensaios, 56. São Paulo: Ática, 1978.

ZANON, D. A ação dos bispos e a orientação tridentina em São Paulo (1745-1796). 1999. Dissertação (Mestrado em História) - Instituto de Filosofia e Ciências Humanas, Universidade Estadual de Campinas, Campinas. Disponível em: http://bit.do/faYDW. Acesso em: 28 set. 2019.

\section{ANEXO}

De acordo com Megale e Toledo Neto (2005, p. 147-148), seguem as normas adaptadas:

- A transcrição do manuscrito será conservadora, isto é, será o mais próxima possível do documento original;

- $\quad$ As abreviaturas deverão ser desenvolvidas e as letras omitidas na mesma serão assinaladas em itálico;

- $\quad$ Quando houver palavras escritas juntas no documento original, serão separadas.

- A pontuação presente no documento original deverá ser fielmente reproduzida na transcrição. E nos locais em que houver maior espaço intervalar, deverá ser marcado na transcrição: [espaço];

- $\quad$ A acentuação do documento original deverá ser reproduzida com rigor;

- $\quad$ O emprego de letras maiúsculas e minúsculas deverá ser fielmente mantido tal qual se encontra nos manuscritos; 
- $\quad$ Serão inseridos em notas de rodapé eventuais erros cometidos pelo escriba ou copista;

- $\quad \mathrm{Na}$ transcrição, serão inseridas entre os sinais $<>$ as inserções realizadas por parte do escriba ou copista, na mesma localização nas quais se encontram no documento original;

- $\quad$ As supressões realizadas pelo escriba ou copista deverão ser tachadas. Já em relação às repetições não suprimidas pelos mesmos no manuscrito, elas deverão, na transcrição, ser colocadas entre colchetes duplos [[ ]];

- As intervenções realizadas por terceiros no manuscrito deverão ser informadas ao final da transcrição com a localização indicada;

- Serão raras as intervenções por parte do editor, ocorrendo somente em situações de absoluta necessidade e devem, quando realizadas, ser inseridas entre colchetes;

- Q Quando alguma letra ou palavra estiver ilegível por deterioração, deve ser indicada entre colchetes da seguinte maneira: [ilegível];

- Se houver ocorrência de trecho ilegível por deterioração que seja mais longo, de trecho riscado ou completamente anulado, deverá ser inserida a informação pertinente entre colchetes e sublinhada;

- Deverá ser mantida, na transcrição, a divisão das linhas tal qual apresenta-se no documento original e a mudança de fólio deverá ser marcada com o respectivo número entre duas barras verticais, por exemplo: ||7r.|| ||7v.|| ||2r.|| ||2v.|| 